Original Research Paper

\title{
Robustness of XFEM Method for the Simulation of Cracks Propagation in Fracture Mechanics Problems
}

\author{
Aniello Riccio, Umberto Caruso, Antonio Raimondo and Andrea Sellitto \\ Department of Industrial and Informatics Engineering, Second University of Naples, Aversa (CE), Italy
}

\author{
Article history \\ Received: 11-07-2016 \\ Revised: 08-08-2016 \\ Accepted: 13-08-2016 \\ Corresponding Author: \\ Anielo Riccio \\ Department of Industrial and \\ Informatics Engineering, \\ Second University of Naples, \\ Aversa (CE), Italy \\ Email: aniello.riccio@unina2.it
}

\begin{abstract}
In the present paper a numerical sensitivity analysis is presented with the aim to assess the effectiveness of the X-FEM method for fracture mechanics applications. Different test cases have been adopted for the numerical analyses to point out the X-FEM method behavior in 2-D and 3$\mathrm{D}$ elastic and elasto-plastic conditions. Comparisons with a standard ductile damage model have been carried out to highlight the advantages of the XFEM method in terms of mesh size and shape independency when simulating cracks propagation.
\end{abstract}

Keywords: XFEM, Crack Propagation, Fracture Mechanics

\section{Introduction}

The standard Finite Element Method (FEM) provides substantial advantages in dealing with continuous field problems. However, for discontinues field problems, it is computationally expensive to obtain accurate solutions with polynomial approximations (Zerbst et al., 2016; Mirsayar, 2015). The mesh has to be align with the discontinuity and a considerable refinement is required around discontinuous feature (Mirsayar, 2014; Mirsayar et al., 2014; Mirsayar et al., 2016). In order to eliminate this limitation, the use of the eXtended Finite Element Method (XFEM) is mandatory. The XFEM is a numerical technique able to overcome the limitation of the standard FEM approach when dealing with discontinues field problems and, for this reason, it has wide applications in fracture mechanics problems. The XFEM approximation consists of standard finite elements, which are used in the most part of the domain and enriched elements used in the sub-domain containing the discontinuity. With XFEM it is possible to model the cracks easily and accurately regardless of the adopted discretization and simulate the initiation and propagation of a discrete crack along an arbitrary, solution-dependent path without the requirement of remeshing.

In literature several examples of XFEM methodology applied to fracture mechanics can be found. Wells and Sluys (2001) a combination of the X-FEM method with the cohesive zone model is adopted to study fracture of concrete materials obtaining an excellent agreement between predictions and experiments. Moes and Belytschko (2002) the XFEM method application is extended to the study of self-similar crack growth Phenomena. Zi and Belytschko (2003) a new enrichment technique has been developed for the study of curved cracks. Mariani and Perego (2003) a numerical methodology is proposed to simulate quasi-static cohesive 2-D crack propagation phenomena in quasibrittle materials. Legrain et al. (2005) the stress state around crack tips in finite strain problems has been studied showing how to solve nonlinear fracture mechanics problems with X-FEM, particularly for hyper-elastic materials. Béchet et al. (2005) a novel enrichment scheme is proposed to improve the robustness of the X-FEM method around cracks. Xiao and Karihaloo (2006) the accuracy of X-FEM crack tip fields has been improved by using higher order quadrature. Dumstorff and Meschke (2007) the performance of a number of crack propagation in association to the X-FEM method have been numerically assessed. In several papers the stress intensity factors are evaluated at the tip of a 2D crack by using domain forms of the interaction integrals (Yau et al., 1980). Duarte et al. (2001) a least squares fit method has been used to correctly evaluate the SIFs. Nagashima et al. (2003) the evaluation of the stress intensity factor for bimaterial interface crack problem is performed. Xiao and Karihaloo (2003) the accuracy in determining the SIF directly without extra postprocessing is assessed. Liu et al. (2004) the technique for the direct evaluation of mixed mode SIFs in homogeneous and bi-materials has been improved. Finally, in (Bouhala et al., 2015) XFEM is utilized to model the crack propagation in thermoanisotropic elastic materials. In the present paper a numerical sensitivity analysis is performed to assess the 
effectiveness of the X-FEM method for fracture mechanics applications. Different test cases have been adopted for the numerical analyses to point out the XFEM method behavior in 2-D and 3-D elastic and elasto-plastic conditions. Comparisons with a standard ductile damage model have been carried out to highlight the advantages of the X-FEM method in terms of mesh size and shape independency when simulating cracks propagation. A final comparison with experimental data for a $\mathrm{CCt}$ specimen in tension have demonstrated the accuracy of the solution, in terms of load-displacement curves, obtained with the X-FEM formulation. In section 2 a brief overview of the theoretical background of X-FEM formulation is provided while in section 3 numerical results are presented and discussed.

\section{Theoretical Background-XFEM}

The theory of XFEM is based on the concept of the unity partition: The presence of discontinuities in an element is taking into account by enriching nodal degrees of freedom with special displacement functions. Considering with $\Gamma$ the crack plane, with $\Lambda$ the crack tip and with $N$ the set of all nodes, defining $N_{\Gamma}$ the nodes crossed by the discontinuity and $N_{A}$ the nodes on the crack tip, as shown in Fig. 1, the approximation of the displacement with the new sets of functions is:

$$
u^{h}(x) \sum_{\text {IeN }} N_{1}(x)\left\lfloor u_{1}+H(x) a_{j}+\sum_{\alpha-1}^{4} \phi_{\alpha}(x) b_{K}^{\alpha}\right\rfloor
$$

Where:

$$
\begin{aligned}
& u=\text { Nodal solution } \\
& H(x)=\text { Heaviside } \\
& u_{I}=\text { FEM solution } \\
& N_{I}=\text { Shape functions } \\
& a_{I}=\text { Nodal enriched degree of freedom vector } \\
& \phi_{\alpha}(\mathrm{x})=\text { Asymptotic crack-tip functions } \\
& \mathrm{b}_{\mathrm{I}}^{\alpha}=\text { Nodal enriched degree of freedom vector }
\end{aligned}
$$

The first term of the previous equation is applied to all nodes of the model, the second term is applied to those nodes whose shape function support is cut by the crack interior $\left(N_{\Gamma}\right)$ and the last term is applied to the nodes whose shape function support is cut by the crack tip $\left(N_{\Lambda}\right)$. Further details of the X-FEM formulation and its application to fracture mechanics problems can be found in (Wells and Sluys, 2001; Moes and Belytschko, 2002; Zi and Belytschko, 2003; Mariani and Perego, 2003; Legrain et al., 2005; Béchet et al., 2005; Xiao and Karihaloo, 2006; Dumstorff and Meschke, 2007; Yau et al., 1980; Duarte et al., 2001; Nagashima et al., 2003; Xiao and Karihaloo, 2003).

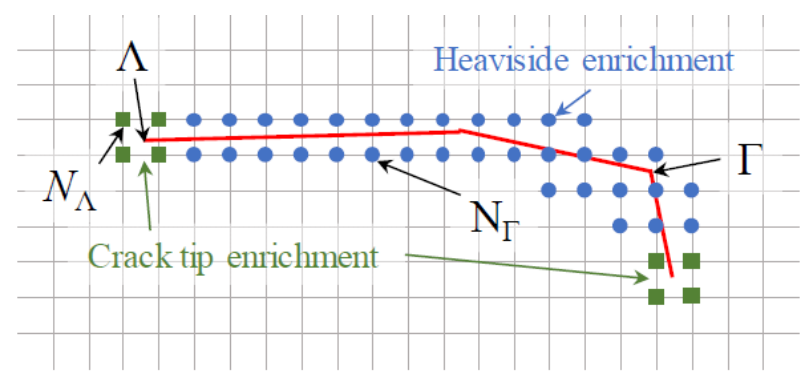

Fig. 1. Crack tip

\section{Numerical Applications}

In order to assess the X-FEM capabilities for fracture mechanics applications, test cases reported in (Liu et al., 2004; Moes et al., 1999; Hansbo and Hansbo, 2004; Song et al., 2006; Giner et al., 2009; ATB, 2007) have been analyzed with Abaqus ${ }^{\mathrm{TM}}$ and compared to a Ductile damage model. The aim of this numerical sensitivity analysis is to evaluate the mesh influence on X-FEM and ductile damage model crack path predictions in 2-D, 3$\mathrm{D}$, elastic and elasto-plastic conditions in order to demonstrate the effectiveness of the X-FEM method when dealing with fracture mechanics applications. A final numerical application on the CCT specimen taken from (ATB, 2007) has shown the accuracy of the XFEM formulation results by means of comparison with experiment data in terms of load Vs displacement curve.

\section{D Test Case \#1-Elastic Conditions}

The first analyzed test case is a notched 2D plate subjected to tension load. The geometry of the specimen and the boundary conditions are described in Fig. 2. The load has been simulated using applied tensile displacements on both side of the plate as shown in Fig. 2.

The material considered for this first application is steel, considered, for this first application, linearly elastic. The material proprieties used in the frame of this first numerical application are show in Table 1.

For the failure initiation, a MAXPS (Max Principal Stress) criterion has been used while for the damage evolution a Strain Energy Release based law has been adopted. For this first application, three different mesh sizes have been used: The first two meshes are structured while the last one is a free mesh. The three FEM models are shown in Fig. 3.

Mesh \#1 is characterized by 25000 CPS4 elements (plane stress, linear and reduced integration) with size of $0.06 \mathrm{~m}$. Mesh \#2 is characterized by 10000 CPS4 elements with size of $0.03 \mathrm{~m}$. Mesh \#3 is characterized by 1557 CPS 4 elements with variable size.

The crack has been modeled with a line and then introduced into the model in the assembly module of Abaqus ${ }^{\mathrm{TM}}$ CAE. As shown Fig. 4, the crack is positioned inside the elements and not on the edges in order to improve the convergence and avoid numerical instabilities. 


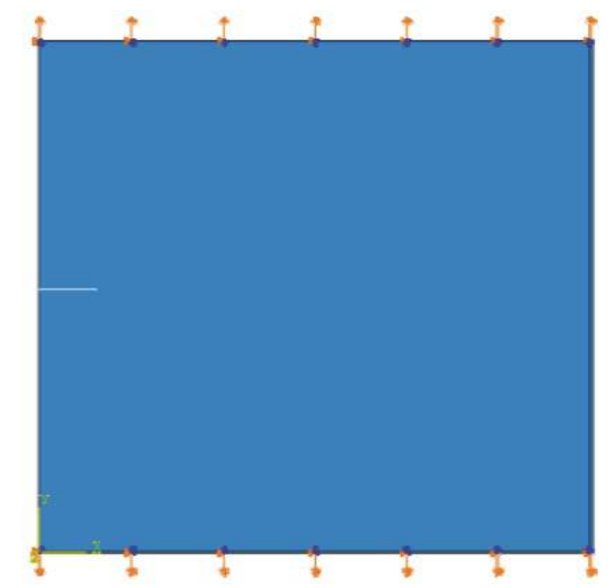

Fig. 2. Test case \#1-Geometrical description and boundary conditions

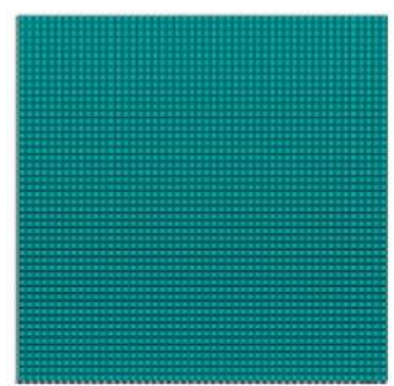

Mesh \#1

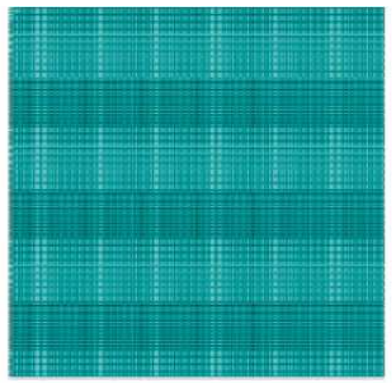

Mesh \#2

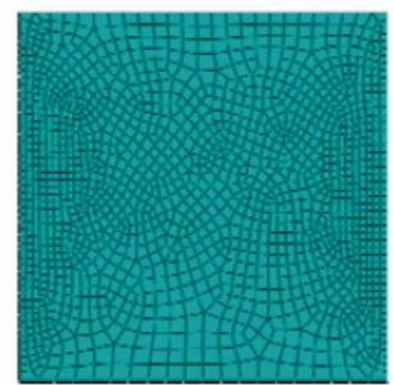

Mesh\#3

Fig. 3. Test case \#1-Mesh configurations definition

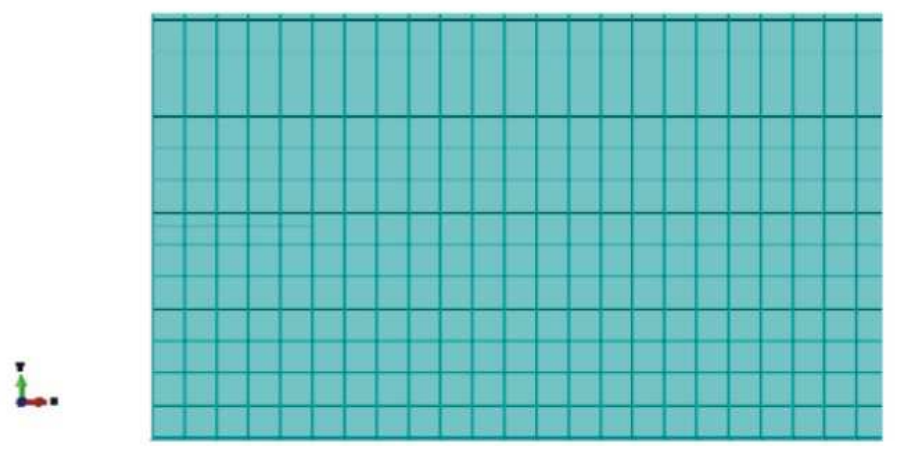

Fig. 4. Test case \#1-Crack positioning 


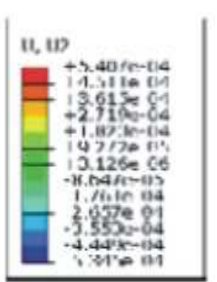

$\stackrel{0}{\mathrm{C}}$

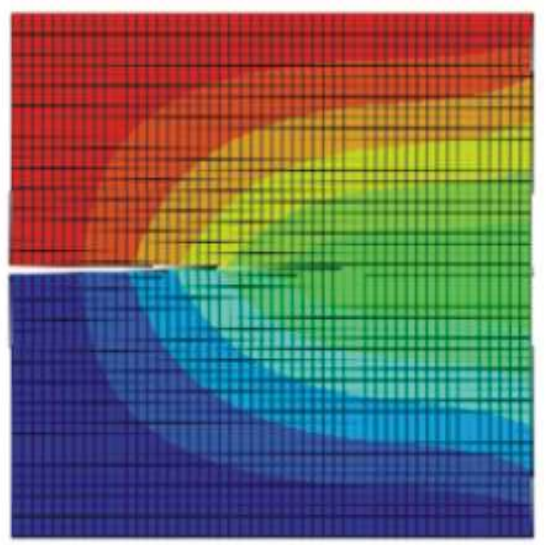

Mesh \#1 - XFEM
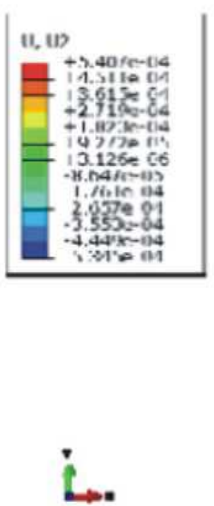

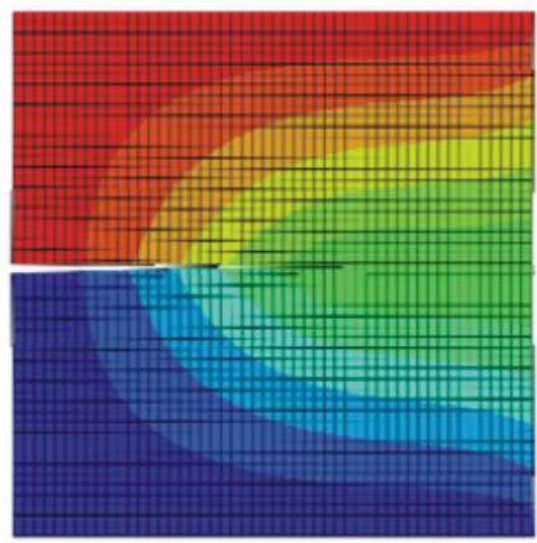

Mesh \#1 - XFEM

Fig. 5. Test case \#1-Mesh \#1-crack propagation-comparison between X-FEM and a ductile damage model
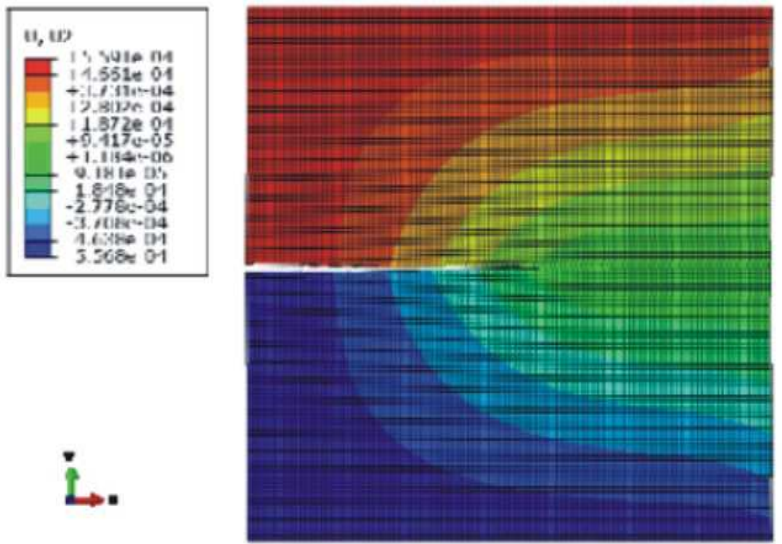

Mesh \#2 - XFEM
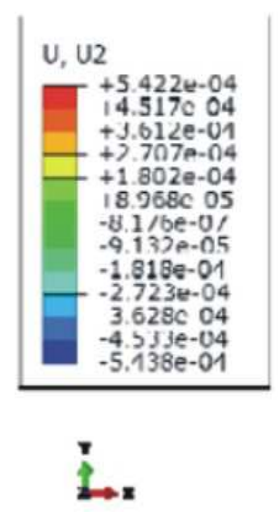

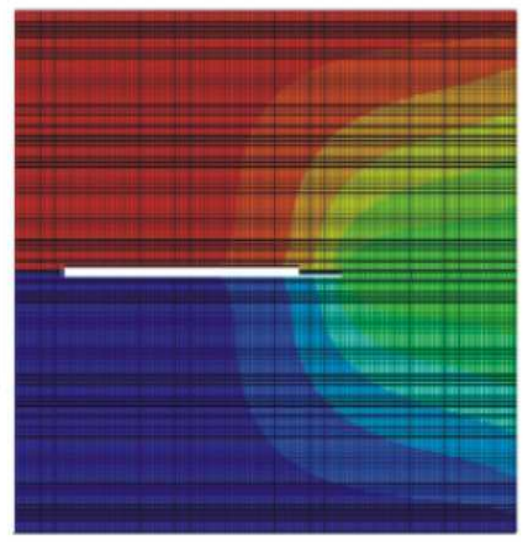

Mesh \#2 - Ductile Damage

Fig. 6. Test case \#1-Mesh \#2-Crack propagation-comparison between X-FEM and a ductile damage model

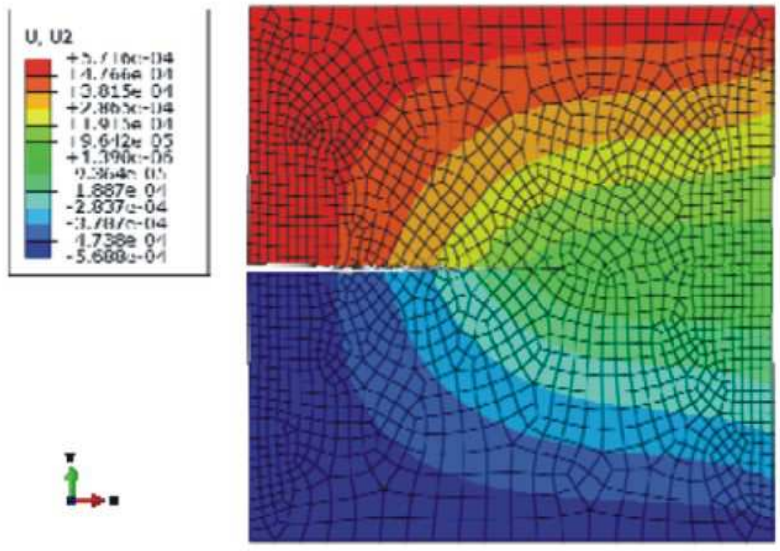

Mesh \#3 - XFEM
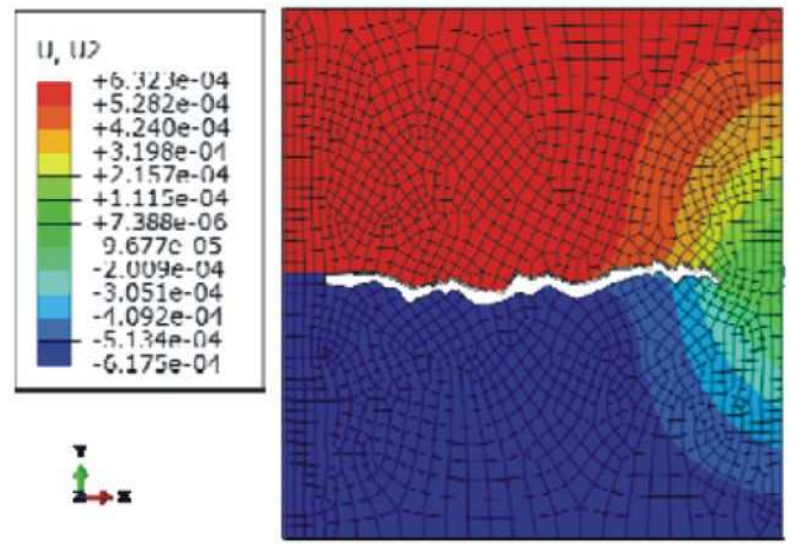

Mesh \#3 - Ductile Damage

Fig. 7. Test case \#1-Mesh \#3-Crack propagation-comparison between X-FEM and a ductile damage model 
Static analyses have been performed including geometrical nonlinearity. As relevant the direction of the crack propagation and the load-displacement curve have been compared. In Fig. 5-7, the propagation direction for the three analyzed configurations using XFEM are compared with the results of analysis performed using Ductile Damage model.

As it can be seen from Fig. 5-7, there are some differences between the discretization used for the XFEM approach and for the Ductile damage method. This is due to the differences in modelling initial crack. As a matter of fact, in the XFEM the initial crack is independent of the mesh while in the Ductile damage the initial crack has to be modeled by removing, before the analysis, the connection between adjacent elements crossed by the crack. From Fig. 5-7, it is possible to observe how the direction of propagation is not sensitive to mesh size variation when using the XFEM method. On the other hands with the Ductile damage model, the direction of propagation is strongly affected by the element size especially when a free mesh is used. The load-displacement curves for the three configurations are shown in Fig. 8.

From Fig. 8, it is possible to observe that the XFEM solution also in terms of the load-displacement curve is not sensitive to mesh size variation Differently from the Ductile damage model.

\section{D Test Case \#2-Elastic-Plastic Conditions}

In order to check the X-FEM effectiveness when the complexity of the material model is improved, the plastic behavior has been considered in the analysis of test case
\#2. As a confirmation of the results found for the first test case, also in this case, the XFEM method outputs are not sensitive to the mesh size and shape, as it can be appreciated in Fig. 9, where the results in terms of load versus applied displacement are shown for the analyzed 2-D configurations.

\section{D Test Case \#3-Elastic Conditions}

The 3D test case \#3 has been modeled by extruding a square plate with side of $3 \mathrm{~m}$. Only two meshes have been analyzed (Fig. 10): The initial mesh with 3600 elements (4 elements along the thickness) and the second mesh with 28800 elements (8 elements along the thickness). C3D8R elements (eight-node brick elements with a reduced integration scheme) have been adopted for this test case.

The boundary conditions are the same as the previous 2D test cases (tensile applied displacement on the edges parallel to the crack plane. In this model, the initial crack has been modeled using a shell plane positioned into the model as shown in Fig. 11.

Also for this test case XFEM and Ductile Damage model have been compared. In Fig. 12-13, the propagation direction for the two analyzed mesh configurations using XFEM are compared with the results of analyses performed using a Ductile Damage model.

Observing the results, also in this case the effectiveness of the XFEM method in terms of mesh size independency compared to the Ductile damage model can be pointed out. This trend is confirmed by the loaddisplacement curves shown in Fig. 14.

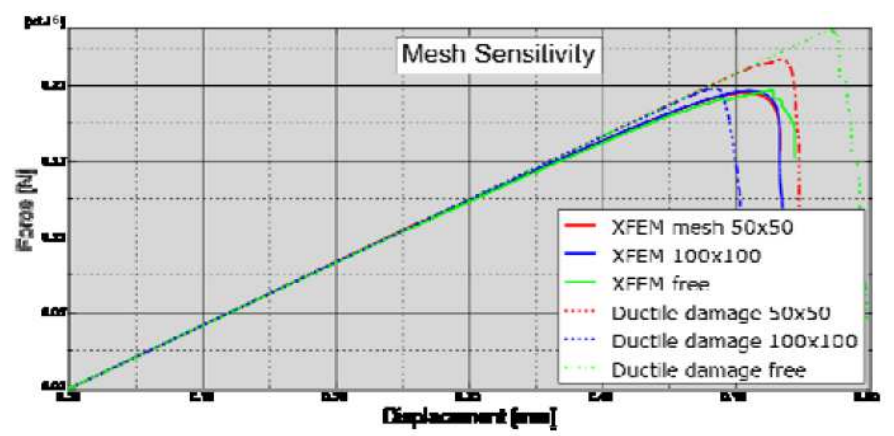

Fig. 8. Test case \#1-Load Vs Displacements-comparison between X-FEM and a ductile damage model

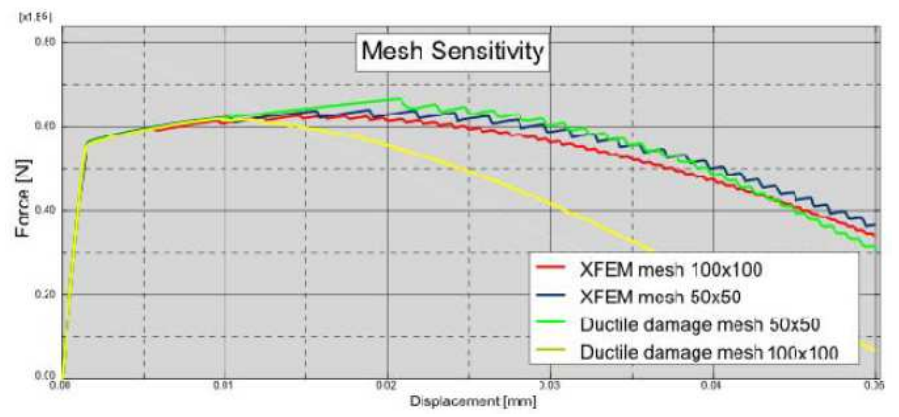

Fig. 9. Test case \#2-Load Vs Displacements-comparison between X-FEM and a ductile damage model 


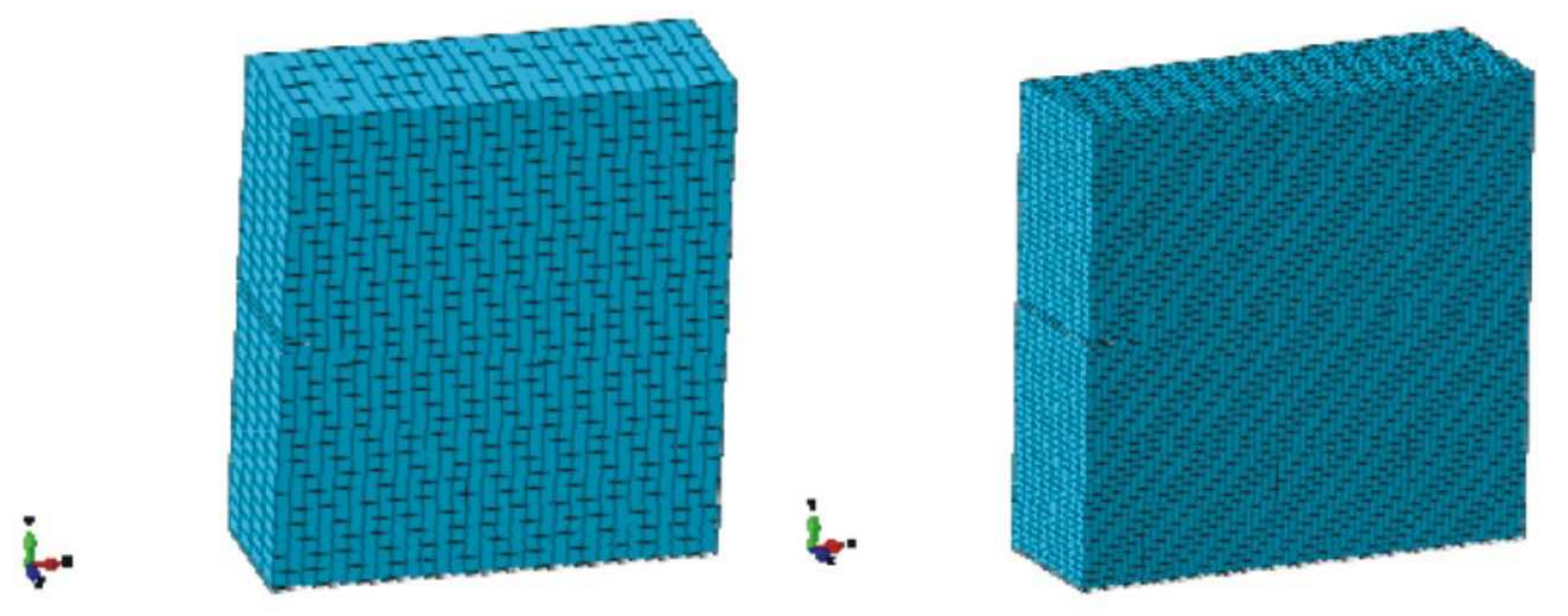

Fig. 10. Test case \#3-Meshes definition

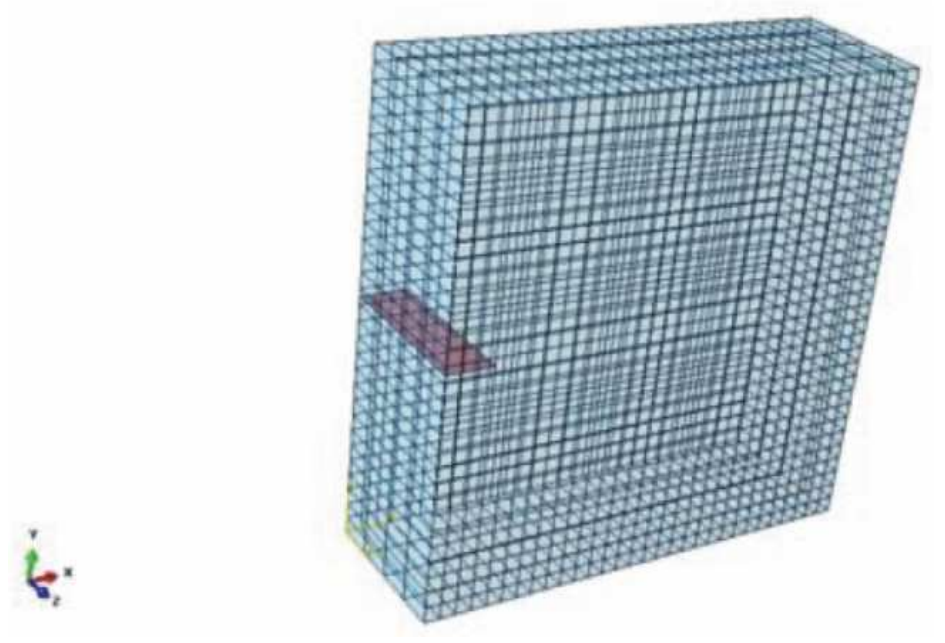

Fig. 11. Test case \#3-Crack positioning

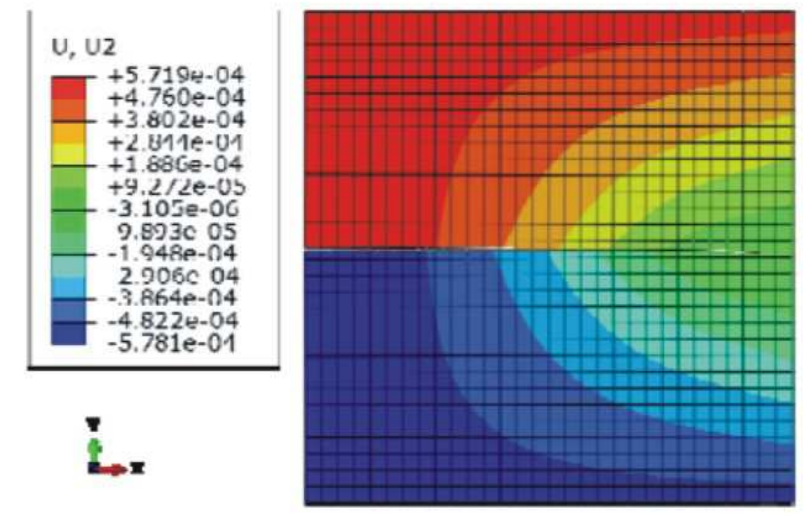

Mesh \#1 - XFEM

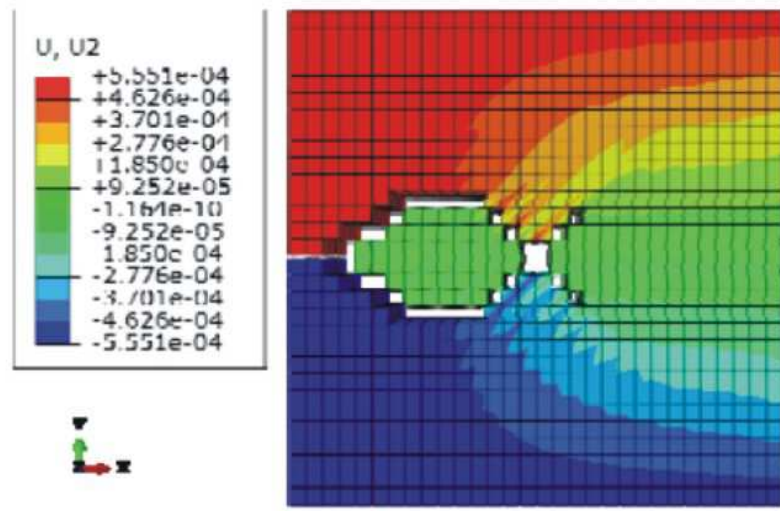

Mesh \#1 - Ductile Damage

Fig. 12. Test case \#3-Mesh \#1-Crack propagation-comparison between X-FEM and a ductile damage model 


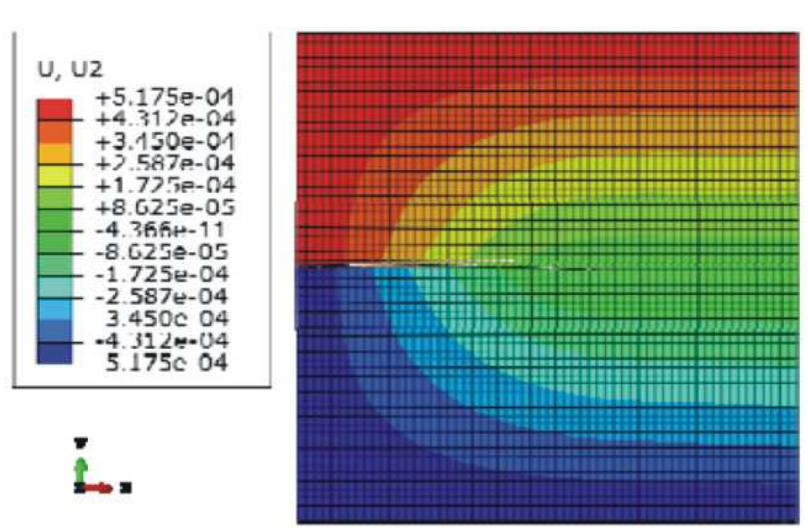

Mesh \#2 - XFEM

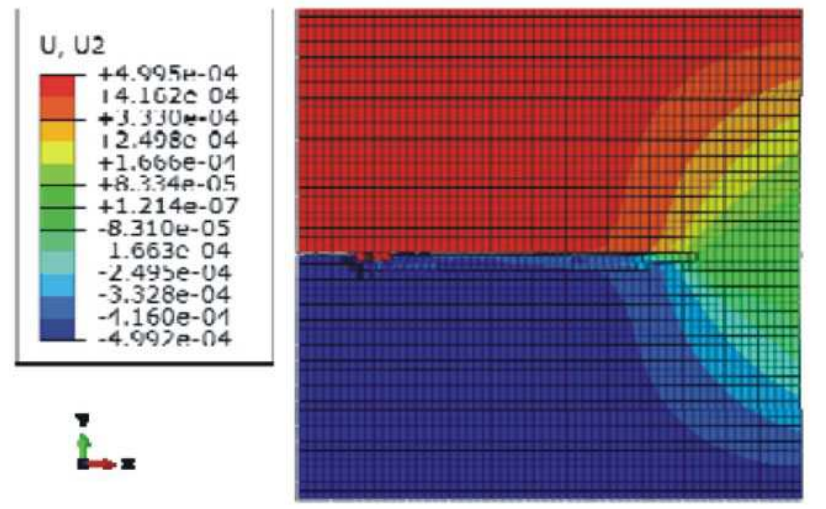

Mesh \#2 - Ductile Damage

Fig. 13. Test case \#3-Mesh \#2-Crack propagation-comparison between X-FEM and a ductile damage model

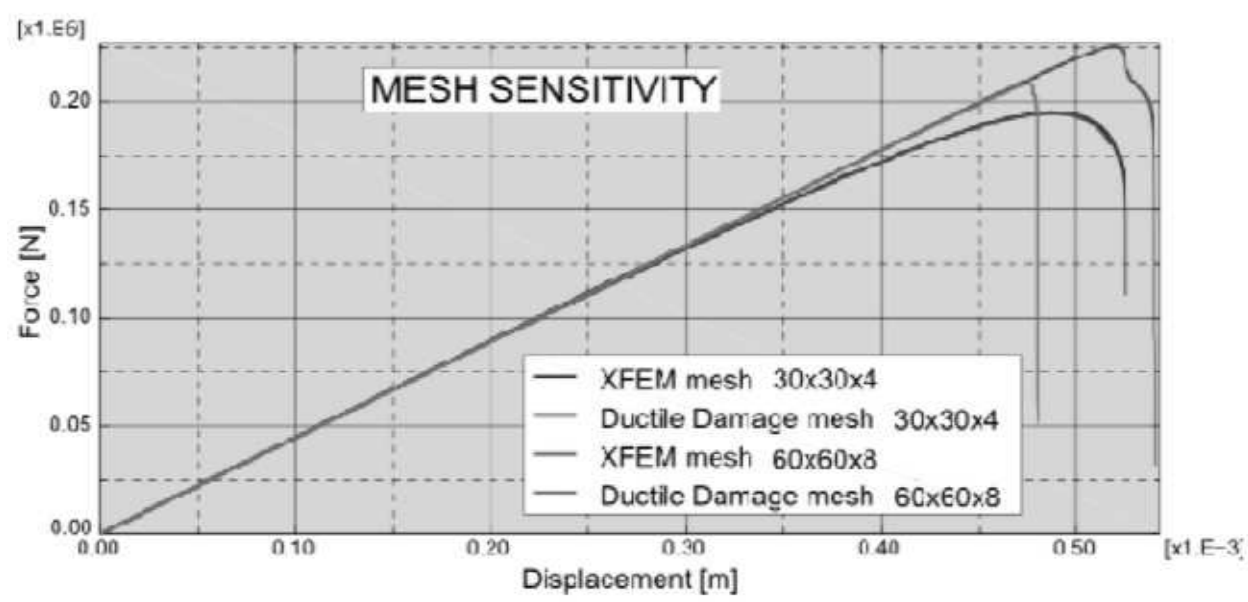

Fig. 14. Test case \#3-Load Vs Displacements curve-comparison between X-FEM and a ductile damage model

\section{CCT Test Case \#4-XFEM Validation}

The last test case investigated is a CCT specimen under tensile load taken from (ATB, 2007). According to (ATB, 2007), where the experimental activity is described, the notched specimen with an initial crack positioned in the notch, has been subjected to a tensile load using two pins inserted into two holes. Figure 15 shows the experimental set-up. This experiment has been numerically simulated by means of the XFEM method and by a Ductile Damage model in order to point out the accuracy of the X-FEM method and to assess the agreement between the results obtained by means of the two analyzed numerical formulations and the experimental data.

The geometrical description of the specimen is shown in Fig. 16 (dimensions in $\mathrm{mm}$ ).

The material used to manufacture the specimen is steel and the properties are shown in Table 1. The reference paper (ATB, 2007) provides also the true stress Vs true strain curve, shown in the Fig. 17, used as input in the FEM software in order to simulate the plastic behavior of the material.

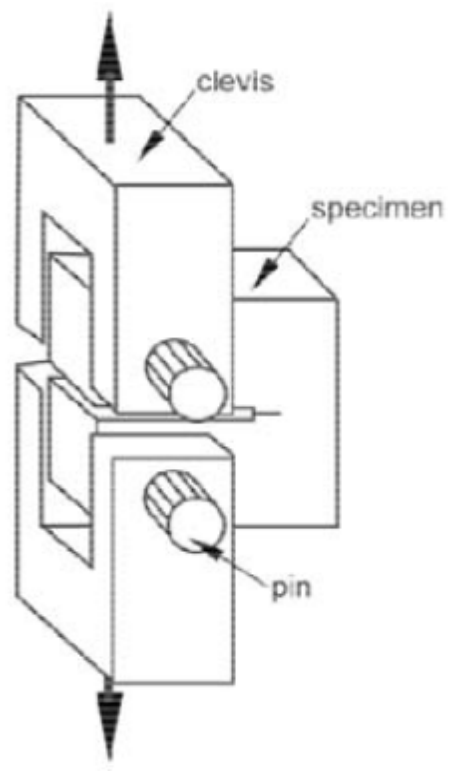

Fig. 15. Test case \#4-Experimental set-up (ATB, 2007) 
Three different mesh shown in Fig. 18 have been considered, two structured mesh and one free mesh, in order to investigate the influence of the mesh on the propagation direction and load-displacement curves. The analyses have been performed using CPS4R elements (quadrilateral, linear, reduced-integration plane stress element).

Mesh \#1 is characterized by 3021 CPS4R elements (plane stress, linear and reduced integration) with size in the propagation area of $1 \mathrm{~mm}$. Mesh \#2 is characterized by 12208 CPS4R elements with size in the propagation area of $0.5 \mathrm{~mm}$. Mesh \#3 is characterized by 881 CPS4R elements with variable size.

In order to simulate the load application through the pins, a rigid body condition has been imposed between the center of the hole and the top half of the circumference.
The displacement has been applied on the node at the center of the circumferences as shown in Fig. 19.

The initial crack has been modeled with a line positioned in the notch, as shown Fig. 20. The enriched elements for the X-FEM formulation have been localized near the notch as shown in Fig. 21 red area.

Static analyses have been performed and the results in terms of propagation direction and load-displacement curves are shown respectively in Fig. 22-24 and Fig. 25b. Also for test case \#4 X-FEM and Ductile Damage models have been compared.

As we it can be seen from Fig. 22-24, once again the XFEM propagation direction is the same for all the analyzed mesh configurations. Indeed, by using the Ductile damage model, the crack direction changes following the elements arrangement.

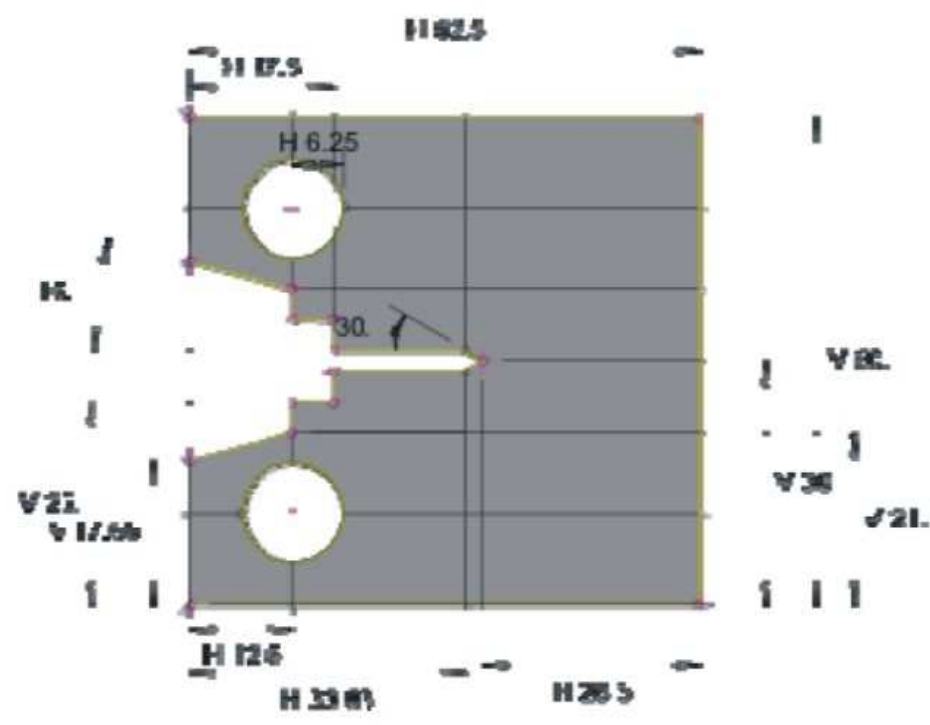

Fig. 16. Test case \#4-Geometrical description

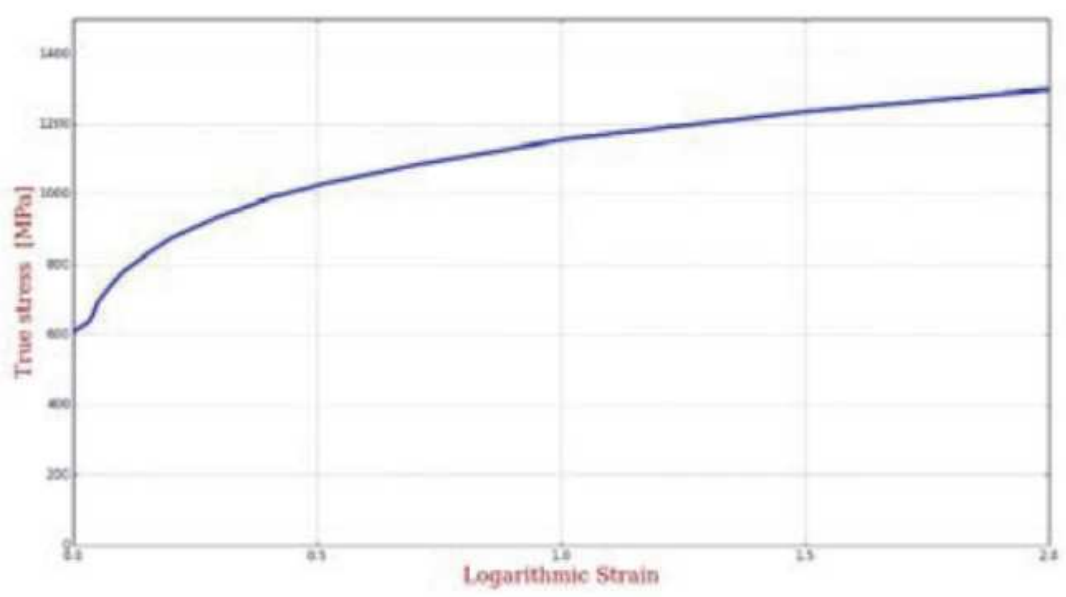

Fig. 17. Test case \#4-True stress Vs true strain curve 


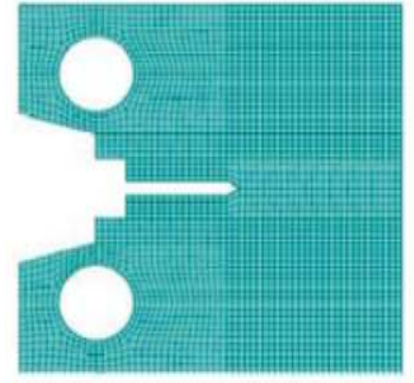

Mesh \#1

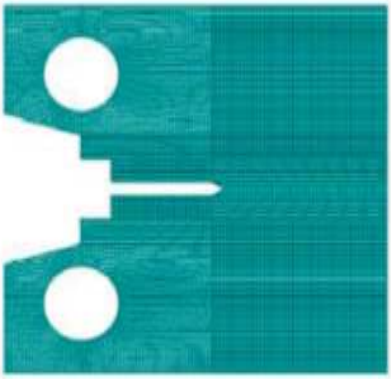

Mesh \#2

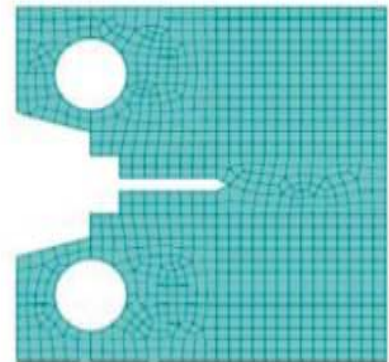

Mesh \#3

Fig. 18. Test case \#4-Mesh configurations definition

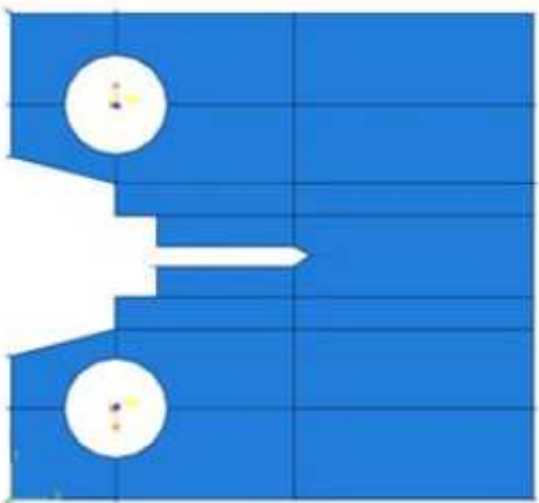

Fig. 19. Test case \#4-boundary conditions

Table 1. Material properties-steel

\begin{tabular}{lll}
\hline Material properties & & \\
\hline Young's modulus & $\mathrm{E}$ & $210 \mathrm{GPa}$ \\
Poisson's ratio & $v$ & 0.3 \\
\hline
\end{tabular}

The load-displacement curves have been created considering the reaction in the y-direction in the center of the holes and the difference between the displacement in the $y$ direction of the two pins center, as shown in Fig. 25a.

From Fig. 25, it is possible to appreciate that, by means of the XFEM method, a maximum load closer to the value obtained from the reference experimental data (Dassault Systems) has been obtained. Table 2 summarizes the maximums loads and the relative displacements for all the analyzed numerical model together with the experimental data.

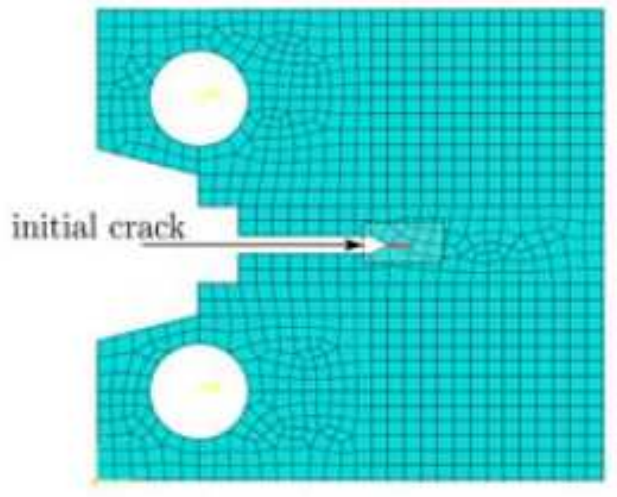

Fig. 20. Test case \#4-initial crack definition

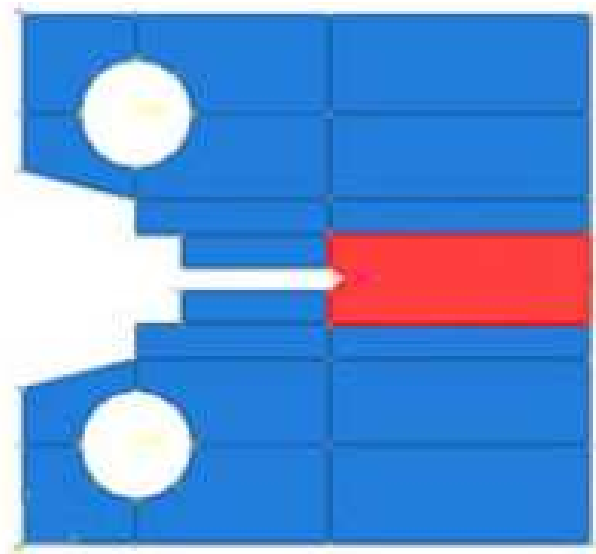

Fig. 21. Test case \#4-enriched elements definition 

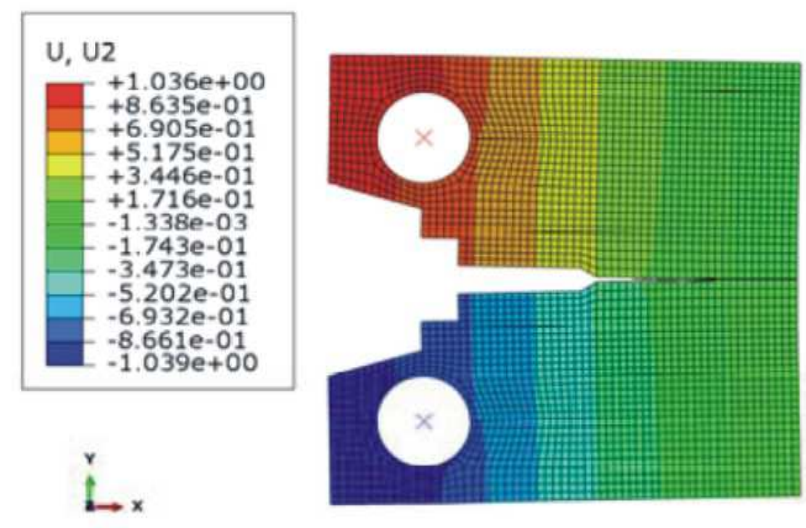

Mesh \#1 - XFEM
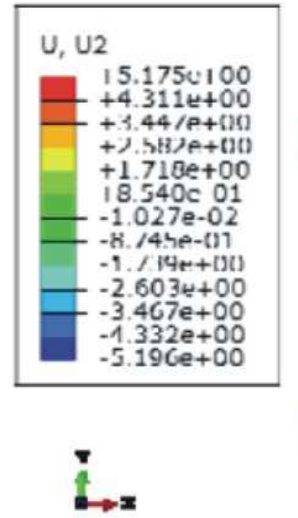

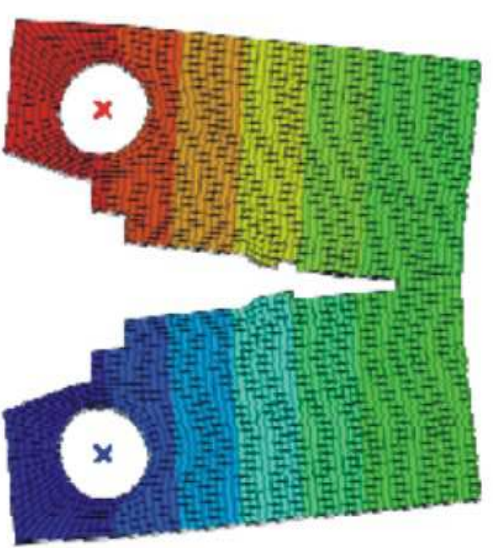

Mesh \#1 - Ductile Damage

Fig. 22. Test case \#4-Mesh \#1-Crack propagation-comparison between X-FEM and a ductile damage model
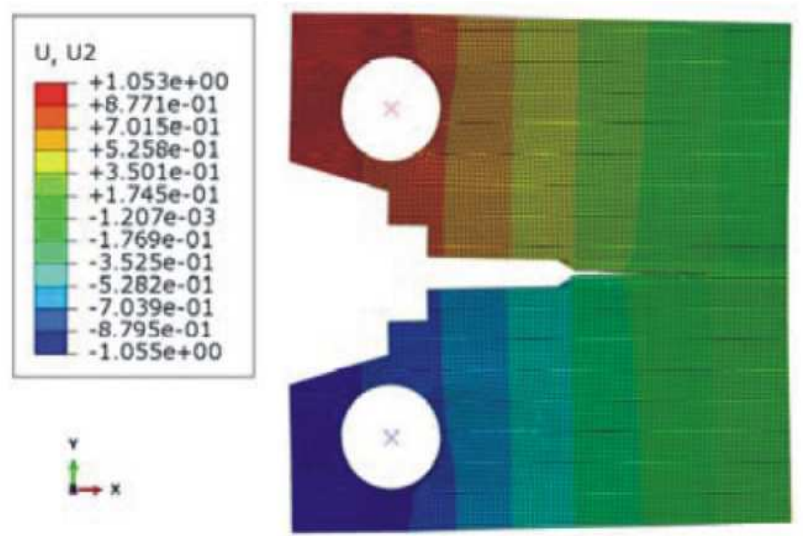

Mesh \#2 - XFEM
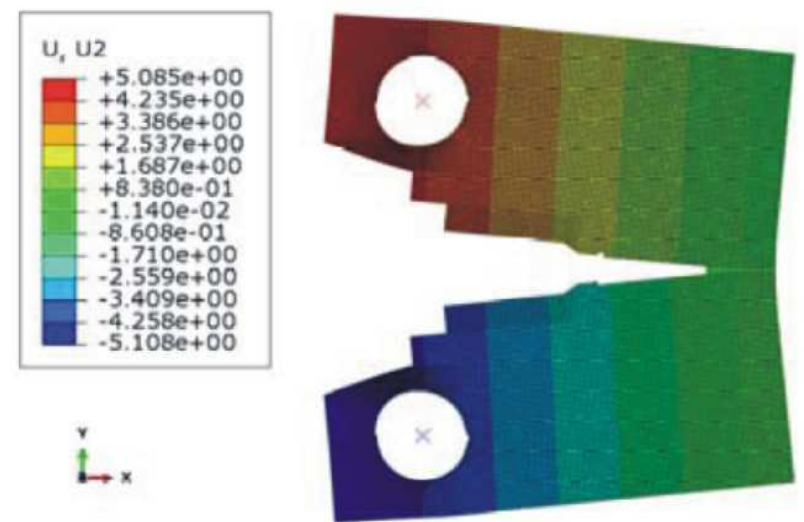

Mesh \#2 - Ductile Damage

Fig. 23. Test case \#4-Mesh \#2-Crack propagation-comparison between X-FEM and a ductile damage model

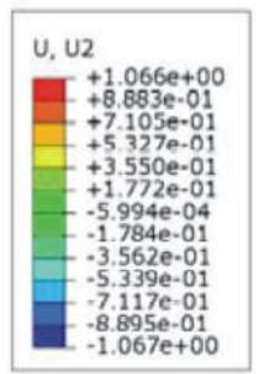

$t_{\rightarrow x}$

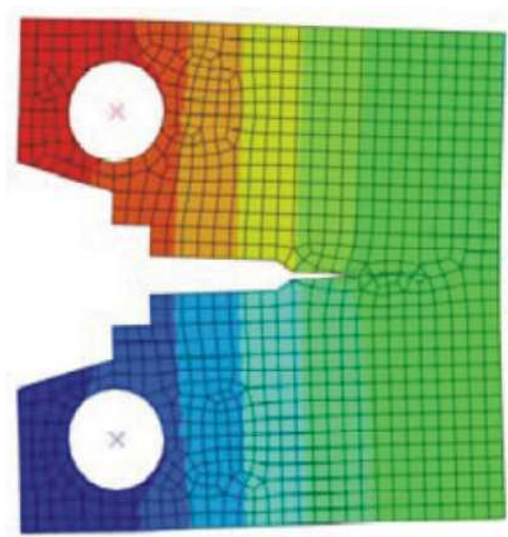

Mesh\#3 - XFEM
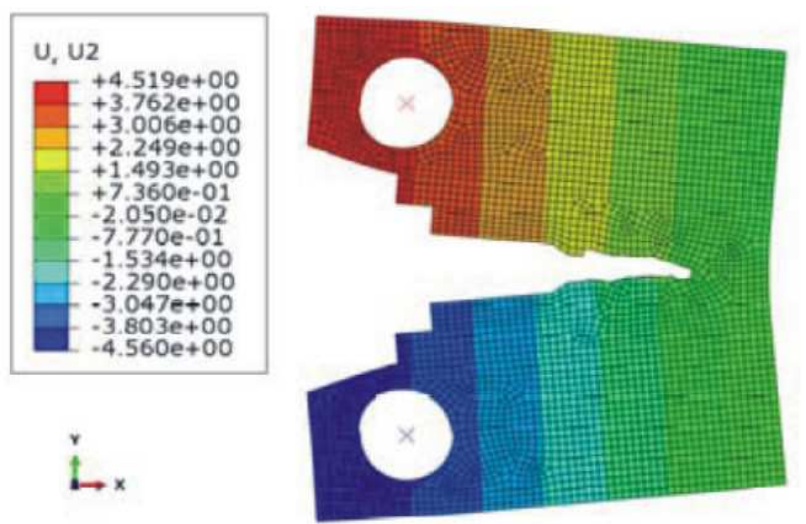

Mesh \#3 - Ductile Damage

Fig. 24. Test case \#4-Mesh \#3-Crack propagation-comparison between X-FEM and a ductile damage model 
a)

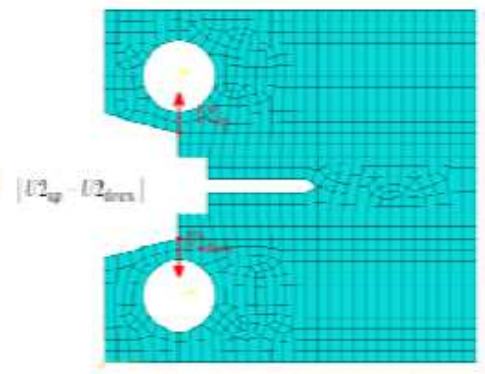

b)

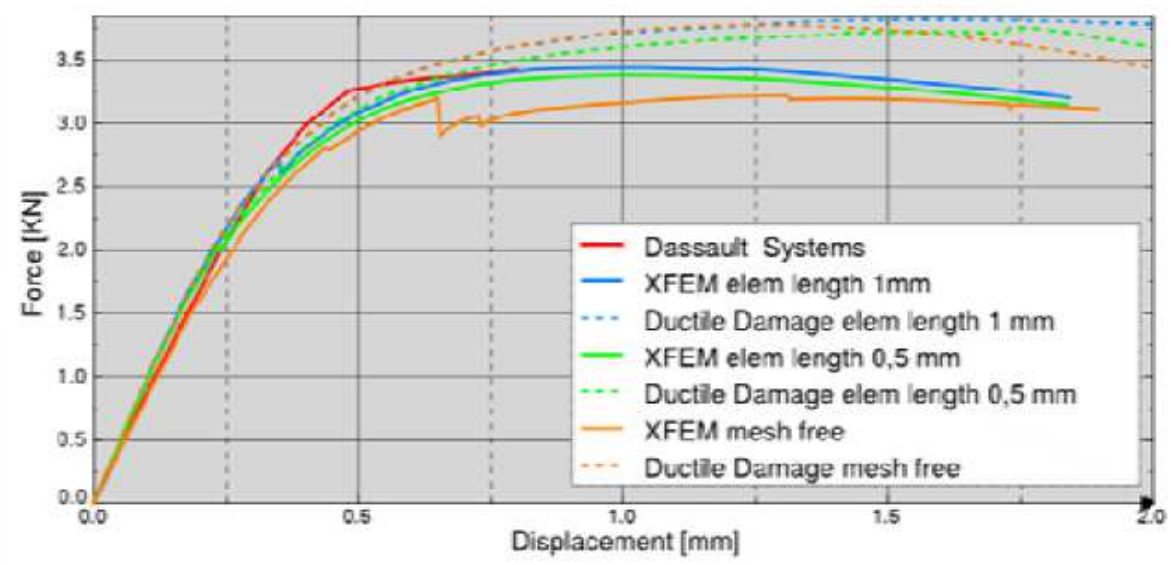

Fig. 25. Test case \#4-(a) definition of the applied displacement for test case \#4; (b) Load Vs Displacements curve-comparison between X-FEM and a ductile damage model

Table 2. Test case \#4-Maximum loads and the relative displacements-comparison among all the adopted numerical models

\begin{tabular}{lll}
\hline Method & $\begin{array}{l}\text { Maximum } \\
\text { load }[\mathrm{N}]\end{array}$ & $\begin{array}{l}\text { Displacement } \\
{[\mathrm{mm}]}\end{array}$ \\
\hline Experiments & 3421 & 0.798 \\
XFEM-Elem length $1 \mathrm{~mm}$ & 3442 & 1.047 \\
XFEM-Elem length $0.5 \mathrm{~mm}$ & 3379 & 0.984 \\
XFEM-Mesh free & 3219 & 1.314 \\
Ductile damage-Elem length $1 \mathrm{~mm}$ & 4104 & 1.774 \\
Ductile damage-Elem length $0.5 \mathrm{~mm}$ & 3837 & 1.585 \\
Ductile damage-Mesh free & 3776 & 1.215 \\
\hline
\end{tabular}

Table 3. Test case \#4-CPU time spent to perform the analyses on test case \#4 with X-FEM element based formulation and with the ductile damage model

\begin{tabular}{|c|c|c|c|}
\hline \multirow[b]{2}{*}{ Method } & \multicolumn{3}{|l|}{ CPU time $[\mathrm{s}]$} \\
\hline & Initial mesh & Fit mesh & Free mesh \\
\hline XFEM & 39 & 176 & 28 \\
\hline Ductile damage & 56 & 444 & 80 \\
\hline
\end{tabular}

Another relevant advantage in using the XFEM approach is the reduced computational cost with respect to standard ductile damage models when simulation fracture mechanics related phenomena. Table 3 shows the CPU time spent when performing the analyses above mentioned for test case \#4.

\section{Conclusion}

A numerical sensitivity analysis has been performed in this study to point out the effectiveness of the X-FEM method for fracture mechanics applications. Numerical analyses on different test cases in 2-D and 3-D elastic and elasto-plastic conditions, have been performed. In these conditions, comparisons with a standard ductile damage model have shown the advantages of the X-FEM method in terms of mesh size and shape independency when simulating cracks propagation. A final numerical application on a CCT specimen demonstrated the accuracy of the X-FEM solution with respect to ductile damage models and confirmed the invariance of the crack propagation direction with mesh size and shape changes.

\section{Acknowledgment}

Authors would like to thank Carolin Petiot and Jeanmathieu Guimard from EADS Innovation Works (Suresnes Cedex-France) for the support provided in performing the activities presente in this paper.

\section{Author's Contributions}

All the authors contributed equally to prepare, develop and carry out this manuscript. 


\section{Ethics}

This article is original. Authors declare that are not ethical issues that may arise after the publication of this manuscript.

\section{References}

ATB, 2007. Fracture mechanics study of a compact tension specimen using abaqus/CAE. Abaqus Technology Brief.

Béchet, E., H. Minnebo, N. Moes and B. Burgardt, 2005. Improved implementation and robustness study of the X-FEM for stress analysis around cracks. Int. J. Numer. Methods Eng., 64: 1033-1056. DOI: $10.1002 / \mathrm{nme} .1386$

Bouhala, L., A. Makradi and S. Belouettar, 2015. Thermo-anisotropic crack propagation by XFEM. Int. J. Mech. Sci., 103: 235-246. DOI: 10.1016/j.ijmecsci.2015.09.014

Duarte, C.A., O.N. Hamzeh, T.J. Liszka and W.W. Tworzydlo, 2001. A generalized finite element method for the simulation of threedimensional dynamic crack propagation. Comput. Methods Applied Mech. Eng., 190: 227-262. DOI: $10.1016 / \mathrm{S} 0045-7825(00) 00233-4$

Dumstorff, P. and G. Meschke, 2007. Crack propagation criteria in the framework of X-FEMbased structural analyses. Int. J. Numer. Anal. Methods Geomech., 31: 239-259. DOI: $10.1002 /$ nag.560

Giner, E., N. Sukumar, J.E. Tarancon and F.J. Fuenmayor, 2009. An Abaqus implementation of the extended finite element method. Eng. Fract. Mech., 76: 347-368. DOI: 10.1016/j.engfracmech.2008.10.015

Hansbo, A. and P. Hansbo, 2004. A finite element method for the simulation of strong and weak discontinuities in solid mechanics. Comput. Methods Applied Mech. Eng., 193: 3523-3540. DOI: $10.1016 /$ j.cma.2003.12.041

Legrain, G., N. Moes and E. Verron, 2005. Stress analysis around crack tips in finite strain problems using the extended finite element method. Int. J. Numer. Methods Eng., 63: 290-314. DOI: 10.1002/nme.1291

Liu, X.Y., Q.Z. Xiao and B.L. Karihaloo, 2004. XFEM for direct evaluation of mixed mode SIFs in homogeneous and bi-materials. Int. J. Numer. Methods Eng., 59: 1103-1118. DOI: 10.1002/nme.906

Mariani, S. and U. Perego, 2003. Extended finite element method for quasi-brittle fracture. Int. J. Numer. Methods Eng., 58: 103-126. DOI: 10.1002/nme.761

Mirsayar, M.M., 2014. On fracture of kinked interface cracks-the role of T-stress. Mater. Design, 61: 117-123. DOI: 10.1016/j.matdes.2014.04.074
Mirsayar, M.M., 2015. Mixed mode fracture analysis using extended maximum tangential strain criterion. Mater. Design, 86: 941-947. DOI: $10.1016 /$ j.matdes.2015.07.135

Mirsayar, M.M., F. Berto, M.R.M. Aliha and P. Park, 2016. Strain-based criteria for mixed-mode fracture of polycrystalline graphite. Eng. Fract. Mech., 156: 114-123. DOI: 10.1016/j.engfracmech.2016.02.011

Mirsayar, M.M., M.R.M. Aliha and A.T. Samaei, 2014. On fracture initiation angle near bi-material notcheseffects of first non-singular stress term. Eng. Fract. Mech., 119: 124-131.

DOI: 10.1016/j.engfracmech.2014.02.017

Moes, N. and T. Belytschko, 2002. Extended finite element method for cohesive crack growth. Eng. Fract. Mech., 69: 813-833. DOI: 10.1016/S0013-7944(01)00128-X

Moes, N., J. Dolbow and T. Belytschko, 1999. A finite element method for crack growth without remeshing. Int. J. Numer. Methods Eng., 46: 131-150.

Nagashima, T., Y. Omoto and S. Tani, 2003. Stress intensity factor analysis of interface cracks using XFEM. Int. J. Numer. Methods Eng., 56: 1151-1173. DOI: $10.1002 /$ nme.604

Song, J.H., P.M.A. Areias and T. Belytschko, 2006. A method for dynamic crack and shear band propagation with phantom nodes. Int. J. Numer. Methods Eng., 67: 868-893. DOI: 10.1002/nme.1652

Wells, G.N. and L.J. Sluys, 2001. A new method for modelling cohesive cracks using finite elements. Int. J. Numer. Methods Eng., 50: 2667-2682. DOI: $10.1002 /$ nme. 143

Xiao, Q.Z. and B.L. Karihaloo, 2003. Direct evaluation of accurate coefficients of the linear elastic crack tip asymptotic field. Fatigue Fract. Eng. Mater. Struct., 26: 719-729. DOI: 10.1046/j.1460-2695.2003.00648.x

Xiao, Q.Z. and B.L. Karihaloo, 2006. Improving the accuracy of XFEM crack tip fields using higher order quadrature and statically admissible stress recovery. Int. J. Numer. Methods Eng., 66: 13781410. DOI: $10.1002 /$ nme. 1601

Yau, J.F., S.S. Wang and H.T. Corten, 1980. A mixedmode crack analysis of isotropic solids using conservation laws of elasticity. J. Applied Mech., 47: 335-341. DOI: 10.1115/1.3153665

Zerbst, U., M. Vormwald, R. Pippan, H.P. Gänser and C. Sarrazin-Baudoux et al., 2016. About the fatigue crack propagation threshold of metals as a design criterion-a review. Eng. Fract. Mech., 153: 190-243. DOI: 10.1016/j.engfracmech.2015.12.002

Zi, G. and T. Belytschko, 2003. New crack-tip elements for XFEM and applications to cohesive cracks. Int. J. Numer. Methods Eng., 57: 2221-2240. DOI: $10.1002 / \mathrm{nme} .849$ 